\title{
Acute renal failure due to an upper ureteral stone and endoscopic surgery
}

\author{
Viroj Wiwanikit
}

Received: 3 April 2010/Accepted: 27 April 2010/Published online: 9 May 2010

(C) Springer-Verlag 2010

Editor, I read the recent case report by Shen et al. [1] with a great interest. Shen et al. [1] mentioned that they successfully treated the acute renal failure due to an upper ureteral stone and endoscopic surgery. Indeed, the acute renal failure due to an upper ureteral stone is not a surprising condition. The important point for this condition is the diagnosis. The most non-invasive diagnostic approach should be selected. Recently, Elwagdy et al. [2] noted that the 3D US methods in case of obstructive uropathy have proved to be useful as an easy, mobile and non-invasive diagnostic tool. Focusing on management, removal of obstruction is the requirement for solving of the renal failure problem. In this case [1], the use of minimally invasive surgery, endoscopic approach can be successful. This finding can add to the recent evidence that the endoscopic technique, retrograde and/or antegrade, can bring complete recovery of acute renal failure due to foreign body obstruction of kidney [3].

\section{References}

1. Shen W, Li W, Pan J, Yan J, Xiong E, Li L, Zhou Z, Song B, Lu G (2010) Specific management of acute renal failure caused by an upper ureteral stone in a solitary pelvic kidney. Urol Res (epub ahead of print)

2. Elwagdy S, Ghoneim S, Moussa S, Ewis I (2008) Threedimensional ultrasound (3D US) methods in the evaluation of calcular and non-calcular ureteric obstructive uropathy. World $\mathbf{J}$ Urol 26(3):263-274

3. Eisenberg ML, Lee KL, Stoller ML (2009) Endoscopic management of retained renal foreign bodies. Urology 73(6):1189-1194
V. Wiwanikit ( $\square)$

Wiwanitkit House, Bangkhae, Bangkok 10160, Thailand

e-mail:wviroj@yahoo.com 